\title{
Effect of amino acids and frequency of reuse frying oils at different temperature on acrylamide formation in palm olein and soy bean oils via modeling system
}

\begin{abstract}
This work investigated the underlying formation of acrylamide from amino acids in frying oils during high temperatures and at different times via modeling systems. Eighteen amino acids were used in order to determine which one was more effective on acrylamide production. Significantly the highest amount of acrylamide was produced from asparagine $(5987.5 \mu \mathrm{g} / \mathrm{kg})$ and the lowest from phenylalanine $(9.25 \mu \mathrm{g} / \mathrm{kg})$. A constant amount of asparagine and glutamine in palm olein and soy bean oils was heated up in modelling system at different temperatures $\left(160,180\right.$ and $200{ }^{\circ} \mathrm{C}$ ) and times $(1.5,3,4.5,6,7.5 \mathrm{~min})$. The highest amount of acrylamide was found at $200{ }^{\circ} \mathrm{C}$ for $7.5 \mathrm{~min}(9317$ and $8511 \mu \mathrm{g} / \mathrm{kg})$ and lowest at $160{ }^{\circ} \mathrm{C}$ for $1.5 \mathrm{~min}(156$ and $254 \mu \mathrm{g} / \mathrm{kg})$ in both frying oils and both amino acids. Direct correlations have been found between time $\left(R^{2}=0.884\right)$, temperature $\left(R^{2}=0.951\right)$ and amount of acrylamide formation, both at $\mathrm{p}<0.05$.
\end{abstract}

Keyword: Acrylamide; Asparagine; Frying-oil; Deep-frying; Glutamine 